\title{
Field evaluation of four widely used mosquito traps in Central Europe
}

Renke Lühken ${ }^{1,2^{*}}$, Wolf Peter Pfitzner ${ }^{3}$, Jessica Börstler ${ }^{4}$, Rolf Garms ${ }^{1}$, Katrin Huber ${ }^{1,5}$, Nino Schork ${ }^{5}$, Sonja Steinke ${ }^{2}$, Ellen Kiel ${ }^{2}$, Norbert Becker ${ }^{3,5}$, Egbert Tannich ${ }^{1,6}$ and Andreas Krüger ${ }^{7}$

\begin{abstract}
Background: To monitor adult mosquitoes several trapping devices are available. These are differently constructed and use various mechanisms for mosquito attraction, thus resulting in different trapping sensitivities and efficacies for the various species. Mosquito monitoring and surveillance programs in Europe use various types of mosquito traps, but only a few comparisons have been conducted so far. This study compared the performance of four commercial trapping devices, which are commonly used in Europe.
\end{abstract}

Methods: Four different traps, Biogents Sentinel trap (BG trap), Heavy Duty Encephalitis Vector Survey trap (EVS trap), Centres for Disease Control miniature light trap (CDC trap) and Mosquito Magnet Patriot Mosquito trap (MM trap) were compared in a $4 \times 4$ latin square study. In the years 2012 and 2013, more than seventy 24-hour trap comparisons were conducted at ten different locations in northern and southern Germany, representing urban, forest and floodplain biotopes.

Results: Per 24-hour trapping period, the BG trap caught the widest range of mosquito species, the highest number of individuals of the genus Culex as well as the highest number of individuals of the species Ochlerotatus cantans, Aedes cinereus/geminus, Oc. communis and Culex pipiens/torrentium. The CDC trap revealed best performance for Aedes vexans, whereas the MM trap was most efficient for mosquitoes of the genus Anopheles and the species Oc. geniculatus. The EVS trap did not catch more individuals of any genus or species compared to the other three trapping devices. The BG trap caught the highest number of individuals per trapping period in urban environments as well as in wet forest, while the CDC trap caught the highest number of individuals in the floodplain biotopes. Additionally, the BG trap was most efficient for the number of mosquito species in urban locations.

Conclusion: The BG trap showed a significantly better or similar performance compared to the CDC, EVS or MM trap with regard to trapping efficacy for most common mosquito species in Germany, including diversity of mosquito species and number of mosquitoes per trapping period. Thus, the BG trap is probably the best solution for general monitoring or surveillance programs of adult mosquitoes in Central Europe.

\section{Background}

Most mosquito monitoring and surveillance programs include the monitoring of adults using different types of trapping devices. Due to automatic trapping by aspiration, mosquito traps have the advantage of relative low costs for data collection in combination with a constant effort independent of the operator, resulting in comparable

\footnotetext{
* Correspondence: renke.luehken@uni-oldenburg.de

'Department of Molecular Parasitology, Bernhard Nocht Institute for Tropical

Medicine, Hamburg, Germany

${ }^{2}$ Research Group Aquatic Ecology and Nature Conservation, Carl von

Ossietzky University, Oldenburg, Germany

Full list of author information is available at the end of the article
}

samples from different trapping sites. Therefore, adult traps are commonly used for the inventory of mosquito biodiversity [1], surveillance of invasive mosquitoes at potential introduction sites [2], monitoring of mosquitoborne pathogens [3], or the reduction of mosquito nuisance [4]. However, in the course of increasing attention for mosquitoes due to the worldwide spread of invasive mosquitoes [5-7] and mosquito-borne pathogens [8], also the number of commercially available traps increased, which are distributed as tools for scientific studies or for mosquito control $[4,9,10]$. These trapping devices use various cues for mosquito attraction (e.g. carbon dioxide, heat, water vapour, olfactory lures, or visual cues), which may 
influence trapping efficacies for the different genera or species [11].

Previous studies on the comparison of mosquito traps were predominantly conducted in North and South America [12-14]. Many of these studies focused primarily on the effectiveness of the traps to catch invasive and/or highly vector-competent species (e.g. Aedes albopictus) $[14,15]$. Due to the spread of invasive mosquitoes [16] and mosquito-borne pathogens (e.g. West Nile virus [17]) in Europe, mosquito monitoring activities have substantially increased during recent years $[2,18]$, but only a few studies have compared the efficacy of different mosquito traps for this region. The Mosquito Magnet Commercial Pro caught more mosquito individuals and a wider range of species than the Centres for Disease Control miniature light trap (CDC trap) in Great Britain [19]. In contrast, Reusken et al. [20] found that the CDC trap performed better than the Mosquito Magnet Liberty in the Netherlands. A limited study in Germany compared the Bidirectional Fay-Prince Trap, Biogents Sentinel (BG trap) and Mosquito Magnet Liberty, but did not find significant differences [21]. The most comprehensive comparison of mosquito traps was conducted in northern Italy with the experimental Biogents BG Eisenhans de Luxe, CDC trap and two mosquito traps for the reduction of mosquito nuisance (Acti Power Trap PV 440 and Acti Power Trap MT 250 Plus) [10]. For the collection of Aedes albopictus, a better trapping efficacy was found for the Biogents BG Eisenhans de Luxe compared to the other three trapping devices. Differences between the BG and CDC traps were reported only for Anopheles atroparvus during a trap comparison in Spanish wetlands [22].

Previous nationwide monitoring programs of mosquito species in Europe used different trapping devices, e.g. Mosquito Magnet Liberty Plus in Switzerland [1], the CDC trap and Mosquito Magnet counter-flow trap in Sweden [23], Mosquito Magnet Liberty Plus in Belgium, Netherlands and Luxembourg [1,24], or Heavy Duty Encephalitis Vector Survey trap and BG traps in Germany [25]. However, a comprehensive comparison of trapping efficacies of these adult mosquito traps commonly used in Central Europe has not been conducted and the choice between the different trapping devices is based

Table 1 Sampling locations

\begin{tabular}{|c|c|c|c|c|c|}
\hline ID & Description & $\begin{array}{l}\text { Aggregated } \\
\text { biotop }\end{array}$ & Sampling period & $\begin{array}{l}\text { Temperature during } \\
\text { sampling period }\left[{ }^{\circ} \mathrm{C}\right] \\
\text { (mean, minimum- } \\
\text { maximum range) }\end{array}$ & $\begin{array}{l}\text { Precipitation during } \\
\text { sampling period [mm] } \\
\text { (mean, minimum- } \\
\text { maximum range) }\end{array}$ \\
\hline \multirow[t]{3}{*}{1} & Garden in an urban area & Urban & 05.09.-09.09.2012 & $16.9(8.4-28.4)$ & $0.0(0.0-0.0)$ \\
\hline & & & 10.06.-14.06.2013 & $15.4(5.1-24.3)$ & $2.1(0.0-8.5)$ \\
\hline & & & 30.07.-03.08.2013 & $22.2(13.9-34.9)$ & $1.0(0.0-4.6)$ \\
\hline \multirow[t]{2}{*}{2} & Cattle farm within a suburban environment & Urban & 19.08.-23.08.2013 & $16.9(9.2-24.1)$ & $3.6(0.0-18.0)$ \\
\hline & & & 26.08.-30.08.2013 & $17.3(7.5-24.3)$ & $0.0(0.0-0.0)$ \\
\hline \multirow[t]{5}{*}{3} & Garden in an urban area & Urban & 03.06.-06.06.2012 & $10.2(4.9-15.1)$ & $1.4(0.0-3.9)$ \\
\hline & & & 09.07.-13.07.2012 & $16.0(10.4-22.8)$ & $5.2(0.0-8.2)$ \\
\hline & & & 28.08.-01.09.2012 & $16.2(8.8-24.9)$ & $0.2(0.0-0.6)$ \\
\hline & & & 10.06.-14.06.2013 & $15.6(4.9-24.3)$ & $3.8(0.0-14.8)$ \\
\hline & & & 08.07.-12.07.2013 & $17.2(10.3-25.4)$ & $0.0(0.0-0.0)$ \\
\hline \multirow[t]{4}{*}{4} & Forest in river inundation area & Floodplain & 17.07.-21.07.2012 & $18.0(10.0-27.2)$ & $1.9(0.0-5.3)$ \\
\hline & & & 24.07.-28.07.2012 & $22.6(2.1-33.3)$ & $6.5(0.0-16.8)$ \\
\hline & & & 03.08.-07.08.2012 & $20.4(11.4-32.3)$ & $0.1(0.0-0.7)$ \\
\hline & & & 13.08.-17.08.2012 & $21.2(9.4-33.6)$ & $1.9(0.0-9.6)$ \\
\hline $5 a$ & Mixed forest & Wet forest & 04.07.-08.07.2013 & $20.8(12.1-28.8)$ & $0.1(0.0-0.5)$ \\
\hline $5 b$ & Mixed forest & Wet forest & 04.07.-08.07.2013 & $20.8(12.1-28.8)$ & $0.1(0.0-0.5)$ \\
\hline $6 a$ & Cemetery within an urban environment & Urban & 26.08.-30.08.2013 & $17.4(9.2-26.1)$ & $0.0(0.0-0.0)$ \\
\hline $6 b$ & Edge of a wood within an urban environment & Urban & 26.08.-30.08.2013 & $17.4(9.2-26.1)$ & $0.0(0.0-0.0)$ \\
\hline \multirow[t]{2}{*}{7} & Forest in river inundation area & Floodplain & 19.08.-23.08.2013 & $23.6(10.5-35.2)$ & $0.3(0.0-1.3)$ \\
\hline & & & 07.09.-11.09.2012 & $18.4(5.4-30.3)$ & $3.2(0.0-15.9)$ \\
\hline 8 & Forest in river inundation area & Floodplain & 02.09.-06.09.2012 & $17.9(7.6-26.7)$ & $0.0(0.0-0.0)$ \\
\hline
\end{tabular}


on expert judgment or studies from other regions [1]. Therefore, the present study aimed to compare four trapping devices for mosquito adults. Our objectives were (i) to compare the efficacies of traps concerning the variety of mosquito species and the overall number of mosquitoes, as well as (ii) to identify the most efficient trap for different biotopes.

\section{Methods}

Trap comparisons were conducted in the years 2012 and 2013 during 19 sampling periods in ten different locations in northern (3 locations) and southern Germany (7 locations) (Table 1, Figure 1). Locations in northern Germany included gardens in urban areas and a cattle farm, and in southern Germany floodplain areas, a wet forest, a cemetery in an urban environment, and the edge of a wood in an urban environment.

Four different traps were compared, which all have been developed to collect host-seeking mosquitoes by aspiration, but differ in their mechanisms of attraction and trapping: (1) Biogents Sentinel trap (BG trap) (BioGents, Regensburg, Germany, http://www.biogents.com/) with BG Lure sachets (BioGents, GmbH, Regensburg, Germany, http://www.biogents.com/) and $\mathrm{CO}_{2}$ from a gas cylinder, (2) Heavy Duty Encephalitis Vector Survey trap

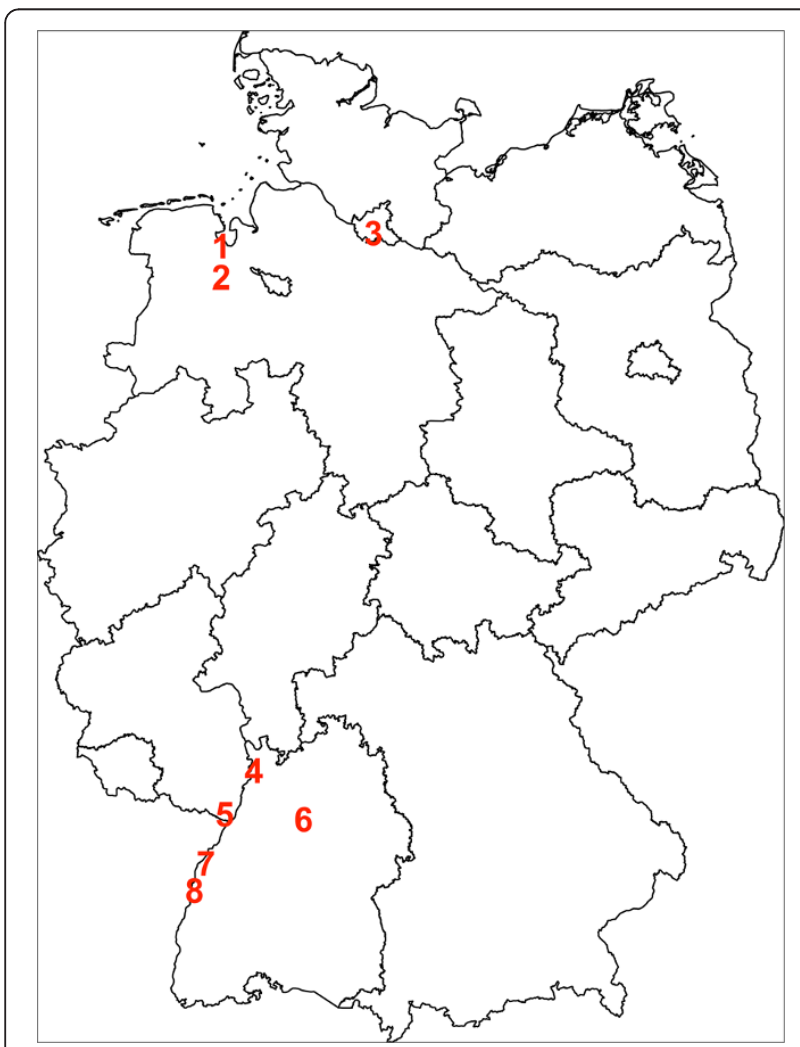

Figure 1 Sampling locations. Sampling locations of the trap comparisons in Germany. Numbers correspond to the IDs in Table 1.
(EVS trap) (BioQuip Products, Rancho Dominguez, California, USA; http://www.bioquip.com/) with $\mathrm{CO}_{2}$ from dry ice (2.5 kg per 24 hours) and without EVS trap lamp, (3) Centres for Disease Control miniature light trap (CDC trap) (BioQuip Products, Rancho Dominguez, California, USA; http://www.bioquip.com/) with CDC bulb and with $\mathrm{CO}_{2}$ from dry ice $(2.5 \mathrm{~kg}$ per 24 hours), which was also put in EVS dry ice containers above the trap, and (4) the Mosquito Magnet Patriot Mosquito trap (MM trap) (MosquitoMagnet, Lititz, Pennsylvania, USA; http://www.mosquitomagnet.com/) with R-Octenol (MosquitoMagnet, Lititz, Pennsylvania, USA; http://www.mosquitomagnet.com/). The MM trap converts propane into $\mathrm{CO}_{2}$. EVS and $\mathrm{CDC}$ traps were hung on low trees or wooden posts (trap opening approximately at $1 \mathrm{~m}$ height), whereas the BG and MM traps were placed on the ground following manufacturers instructions.

A $4 \times 4$ latin square experimental design was applied. At each location, all traps were placed approximately $50 \mathrm{~m}$ from each other at four different sampling points. Every 24 hours, all traps were rotated to the next position to reduce sampling point specific differences. One complete trapping cycle per latin square consisted of four 24-hour trapping periods. Mosquitoes were collected every 24 hours in the late afternoon, killed in a freezer and morphologically identified in the laboratory $[27,28]$. Four morphologically very similar species were summarized as species pairs (Aedes cinereus/geminus, Ochlerotatus excrucians/annulipes, Ochlerotatus sticticus/diantaeus and Culex pipiens/torrentium), because a morphological differentiation is not possible or doubtful in cases where the material is in poor condition. In terms of the taxonomy of Aedini species, the generic names used here follow the system of Becker et al. $[27,28]$ and are not adopted from the revisions of Reinert et al. [29].

Generalized linear mixed models (GLMM) were used to analyse the effect of different trapping devices on the number of caught individuals for all species/genera per trapping period, total number of individuals/species per trapping period and total number of caught individuals/ species per trapping period differentiated for aggregated biotopes. GLMMs allow dependent variables to be modelled while controlling for independent random variables (in this case the latin square number) to test the statistical significance of a fixed independent variable (type of trapping device). Mean and standard errors of differences in least squares means associated with a mixed linear model were calculated. Furthermore, Simpson's diversity index per trapping period was caculated to compare the recorded species diversity among the four trapping devices. Data preparation, visualization and statistical analyses were conducted with $\mathrm{R}$ [30] using 
functions from the packages ggplot2 [31], $\operatorname{lm} 4$ [32], lmerTest [33], plyr [34], sp [35,36], and vegan [37].

\section{Results}

A total of 83 trap comparisons were conducted. However, due to organisational and technical issues, nine trapping periods comprised only three different trapping devices (BG trap, CDC trap, and EVS trap), thus resulting in 323 24-hour sampling periods $(83 \times$ BG trap, $83 \times$ CDC trap, $83 \times$ EVS trap, $74 \times$ MM trap).

During the study 24,094 mosquitoes were caught, belonging to 21 species or morphologically indistinguishable pairs of species (Table 2) and comprising $43 \%$ of the established 49 mosquito species in Germany (Table 2, Additional file 1). All species known to be abundant in Germany and to occur in high density were detected (Table 2) [38]. Most abundant species were Aedes vexans (30.0\%), Aedes cinereus/geminus (17.0\%), Culex pipiens/ torrentium (12.2\%), Ochlerotatus sticticus/diantaeus (9.9\%) and Ochlerotatus cantans (9.7\%). Culex hortensis, Culex territans, and Culiseta morsitans were only caught with one individual. Undetected species are predominantly classified as less common in Germany (Additional file 1). The BG trap showed the best performance for individuals of the genus Culex and the MM trap for the genus Anopheles (Figure 2, Table 3). During the entire study the highest number of species was caught with the CDC trap followed by the BG trap, EVS trap, and MM trap, but the total number of species detected was quite similar between the four trapping devices (Figure 3). However, the BG trap caught significantly more species per trapping period compared to CDC trap, EVS trap, and MM trap, while there were no significant differences between the latter three traps (Figure 4, Table 4). This was also supported by slightly higher species diversity indices for the BG trap (Figure 5).

Table 2 Number and percentage of trapped individuals for the mosquito species caught with the four different trapping devices

\begin{tabular}{|c|c|c|c|c|c|c|c|c|c|c|}
\hline Species & BG & $\%$ & CDC & $\%$ & EVS & $\%$ & MM & $\%$ & Total & $\begin{array}{l}\text { Occurence in } \\
\text { Germany }\end{array}$ \\
\hline Anopheles maculipennis s.l.* & 0 & 0.0 & 18 & 33.3 & 18 & 33.3 & 18 & 33.3 & 54 & +++ \\
\hline Anopheles claviger & 2 & 3.1 & 33 & 50.8 & 9 & 13.8 & 21 & 32.3 & 65 & ++ \\
\hline Anopheles plumbeus & 105 & 33.1 & 51 & 16.1 & 33 & 10.4 & 128 & 40.4 & 317 & ++ \\
\hline Aedes cinereus/geminus & 1,552 & 38.0 & 783 & 19.2 & 725 & 17.7 & 1,027 & 25.1 & 4,087 & ++/proven \\
\hline Aedes rossicus & 6 & 66.7 & 3 & 33.3 & 0 & 0.0 & 0 & 0.0 & 9 & ++ \\
\hline Aedes vexans & 841 & 11.6 & 3,544 & 49.0 & 1,837 & 25.4 & 1,016 & 14.0 & 7,238 & ++++ \\
\hline Ochlerotatus cantans & 1,206 & 51.9 & 565 & 24.3 & 470 & 20.2 & 84 & 3.6 & 2,325 & ++ \\
\hline Ochlerotatus caspius & 1 & 8.3 & 10 & 83.3 & 1 & 8.3 & 0 & 0.0 & 12 & $(+)$ \\
\hline Ochlerotatus communis & 208 & 39.8 & 116 & 22.2 & 116 & 22.2 & 83 & 15.9 & 523 & + \\
\hline Ochlerotatus excrucians/annulipes & 50 & 41.0 & 35 & 28.7 & 25 & 20.5 & 12 & 9.8 & 122 & $(+) /++$ \\
\hline Ochlerotatus geniculatus & 144 & 29.8 & 77 & 15.9 & 49 & 10.1 & 214 & 44.2 & 484 & $(+)$ \\
\hline Ochlerotatus japonicus & 84 & 18.7 & 249 & 55.3 & 4 & 0.9 & 113 & 25.1 & 450 & + \\
\hline Ochlerotatus punctor & 141 & 35.6 & 90 & 22.7 & 103 & 26.0 & 62 & 15.7 & 396 & + \\
\hline Ochlerotatus rusticus & 818 & 38.3 & 470 & 22.0 & 217 & 10.1 & 633 & 29.6 & 2,138 & ++ \\
\hline Ochlerotatus sticticus/diantaeus & 857 & 36.0 & 718 & 30.1 & 424 & 17.8 & 384 & 16.1 & 2,383 & $+++/(+)$ \\
\hline Ochlerotatus spec. & 30 & 68.2 & 6 & 13.6 & 3 & 6.8 & 5 & 11.4 & 44 & \\
\hline Culex hortensis & 0 & 0.0 & 1 & 100.0 & 0 & 0.0 & 0 & 0.0 & 1 & - \\
\hline Culex pipiens/torrentium & 1,398 & 47.5 & 655 & 22.3 & 861 & 29.3 & 29 & 1.0 & 2,943 & $++++/++++$ \\
\hline Culex territans & 0 & 0.0 & 1 & 100.0 & 0 & 0.0 & 0 & 0.0 & 1 & ++ \\
\hline Culiseta annulata & 59 & 16.0 & 107 & 29.0 & 139 & 37.7 & 64 & 17.3 & 369 & ++ \\
\hline Culiseta morsitans & 1 & 100.0 & 0 & 0.0 & 0 & 0.0 & 0 & 0.0 & 1 & + \\
\hline Culiseta spec. & 2 & 66.7 & 0 & 0.0 & 0 & 0.0 & 1 & 33.3 & 3 & \\
\hline Coquillettidia richiardii & 17 & 21.8 & 14 & 17.9 & 20 & 25.6 & 27 & 34.6 & 78 & + \\
\hline Unidentified Culicidae & 18 & 35.3 & 27 & 52.9 & 5 & 9.8 & 1 & 2.0 & 51 & \\
\hline Total & 7,540 & 31.3 & 7,573 & 31.4 & 5,059 & 21.0 & 3,922 & 16.3 & 24,094 & \\
\hline
\end{tabular}

Number and percentage of trapped individuals for the mosquito species caught with the four different trapping devices. Occurrence in Germany classified after Becker et al. [38] (occurrence: $++++=$ massive; $+++=$ abundant; $++=$ frequent; $+=$ regularly; $(+)=$ rare; $-=$ not classified; * species complex includes Anopheles atroparvus, An. daciae, An. maculipennis, An. messeae). 


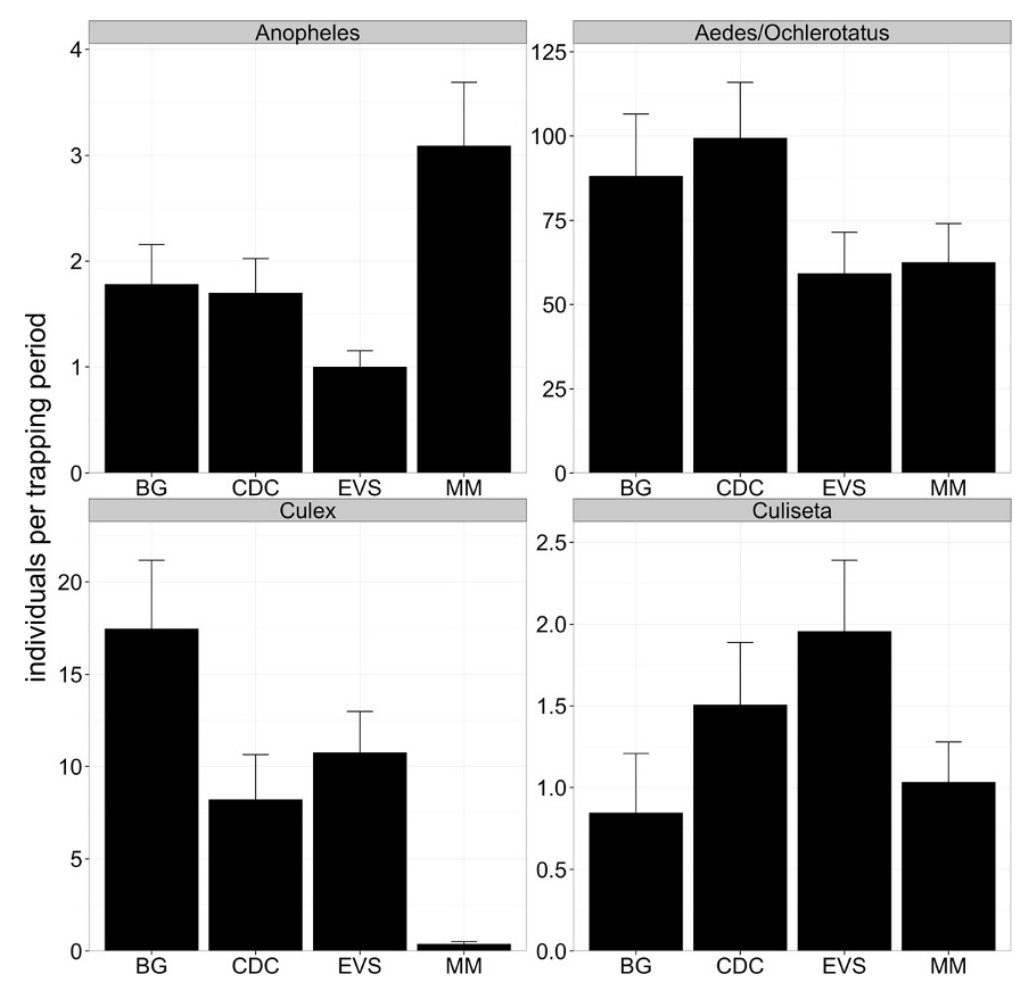

Figure 2 Number of trapped individuals per genera among the four trapping devices. Mean $+/-S E$ number of trapped individuals per trapping period among the four trapping devices. Only mosquito genera caught with more than 100 individuals are shown and trapping periods were only included if the genus was detected with at least one individual in the corresponding trapping period at the sampling location.

Table 3 Statistical differences between the number of trapped individuals per genera among the four trapping devices

\begin{tabular}{lllllll}
\hline $\begin{array}{l}\text { Response } \\
\text { variable }\end{array}$ & Traps & Estimate & SE & DF & t & p \\
\hline Anopheles & BG vs. MM & -0.905 & 0.349 & 300.7 & -2.59 & 0.010 \\
& CDC vs. MM & -0.950 & 0.349 & 300.6 & -2.72 & 0.007 \\
& EVS vs. MM & -1.456 & 0.349 & 300.6 & -4.17 & $<0.001$ \\
Aedes/ & & & & & & \\
Ochlerotatus & BG vs. EVS & 23.570 & 10.264 & 299.1 & 2.30 & 0.022 \\
& BG vs. MM & 23.796 & 10.654 & 299.5 & 2.23 & 0.026 \\
& CDC vs. EVS & 32.398 & 10.260 & 299.0 & 3.16 & 0.002 \\
& CDC vs. MM & 32.624 & 10.650 & 299.5 & 3.06 & 0.002 \\
Culex & BG vs. CDC & 8.933 & 2.807 & 299.2 & 3.18 & 0.002 \\
& BG vs. EVS & 6.475 & 2.807 & 299.2 & 2.31 & 0.022 \\
& BG vs. MM & 16.962 & 2.911 & 300.5 & 5.83 & $<0.001$ \\
& CDC vs. MM & 8.029 & 2.910 & 300.5 & 2.76 & 0.006 \\
& EVS vs. MM & 10.486 & 2.910 & 300.5 & 3.60 & 0.000 \\
Culiseta & BG vs. EVS & -0.963 & 0.328 & 298.5 & -2.93 & 0.004
\end{tabular}

Mean +/-SE differences in least squares means associated with the mixed linear models for the number of individuals per trapping period among the four trapping devices. Only mosquito genera caught with more than 100 individuals are shown and trapping periods were only included if the genus was detected with at least one individual in the corresponding trapping period at the sampling location (only significant differences shown). BG: Biogents Sentinel trap, EVS: Heavy Duty Encephalitis Vector Survey trap, CDC: Centres for Disease Control miniature light trap, MM: Mosquito Magnet Patriot Mosquito trap, Estimate: differences in least squares means, SE: standard error, DF: degrees of freedom, t: t-value, $p$ : $p$ value.

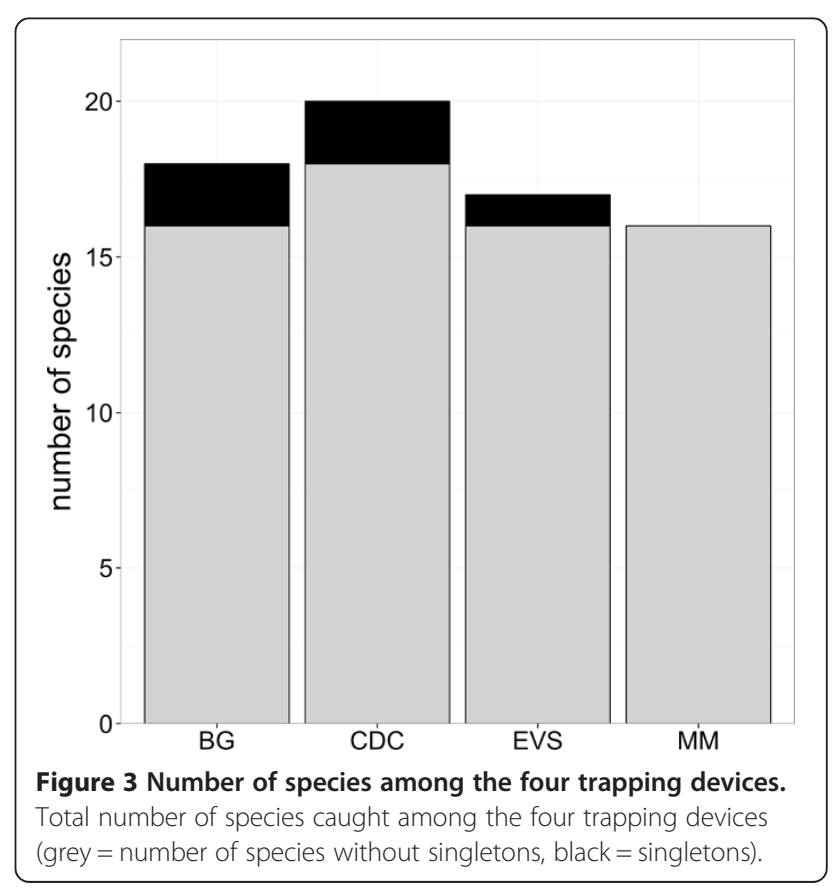




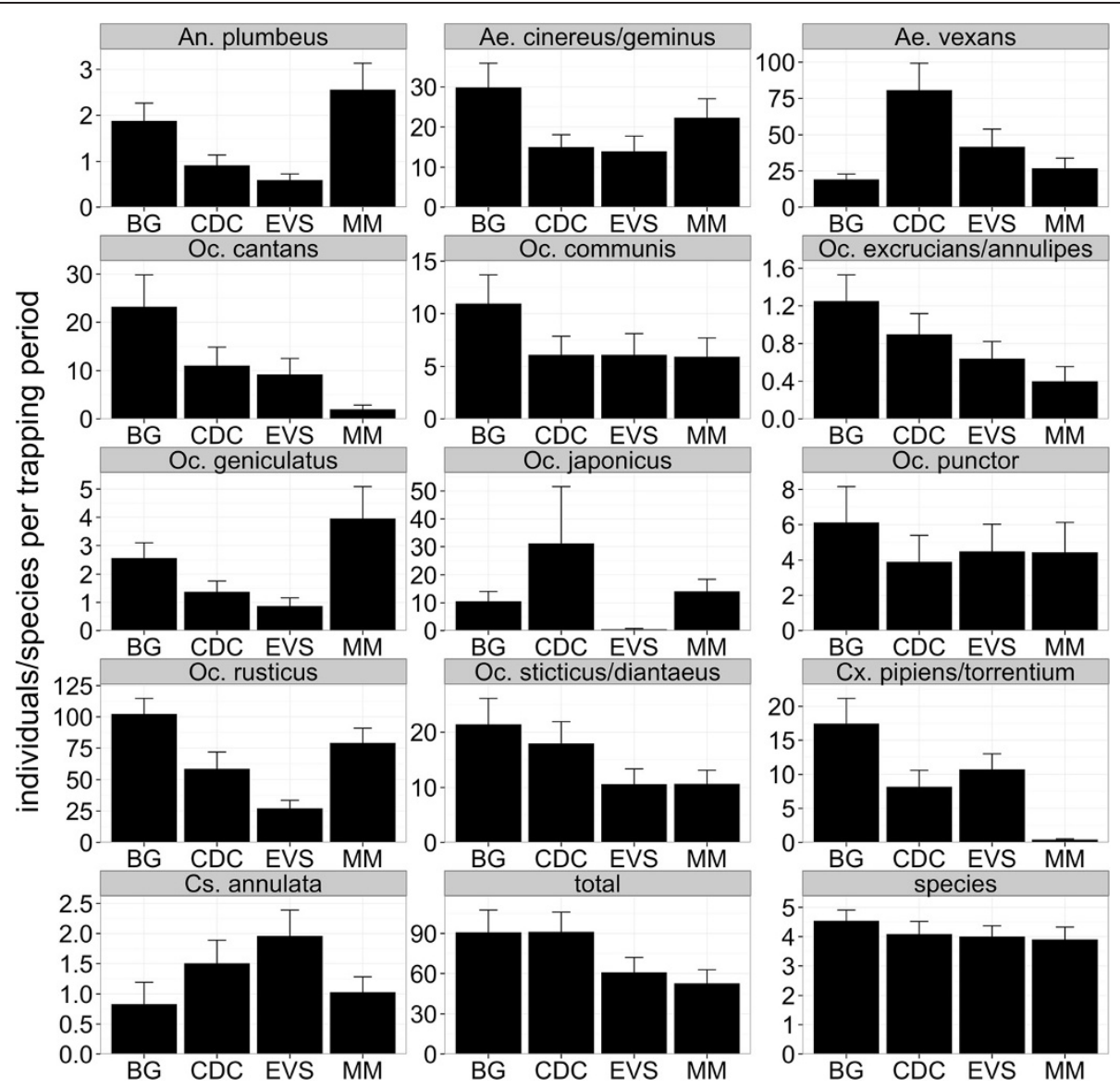

Figure 4 Number of trapped individuals per species and the total number of individuals among the four trapping devices. Mean $+/-S E$ number of trapped individuals per trapping period for each species and the total number of individuals and the mean $+/-S E$ number of species among the four trapping devices. Only mosquito species caught with more than 100 individuals are shown and trapping periods were only included if the species was detected with at least one individual in the corresponding trapping period at the sampling location.

BG and CDC traps caught significantly more mosquitoes per trapping period compared to EVS and MM traps (Figure 4, Table 4). The four trapping devices differed in performance regarding their efficacy to trap individual mosquito species. The BG trap caught significantly more individuals of the species Oc. cantans, Ae. cinereus/geminus, Oc. communis, and Cx. pipiens/torrentium per trapping period. The CDC trap outcompeted the other devices by trapping significantly more $A e$. vexans individuals per trapping period and the MM trap caught significantly more individuals of Oc. geniculatus per trapping period. In contrast, the EVS trap did not outperform for any species. The MM trap caught the smallest number of individuals of the species $C x$. pipiens/torrentium and Oc. cantans per trapping period. Additionally, the CDC trap with light outcompeted the EVS trap without light for Aedes vexans and Ochlerotatus sticticus/diantaeus.

The four traps showed differences in their suitability for the three aggregated biotopes investigated. The BG trap caught significantly more individuals per trapping period in the urban environment as well as in wet forest (Figure 6, Table 5), while the CDC trap caught most individuals per trapping period in the floodplain. Moreover, the BG trap was most efficient for the trapping of the variety of mosquito species per trapping period in an urban environment (Figure 7, Table 6).

\section{Discussion}

Several commercial trapping devices for mosquitoes are available, which are used for nuisance reduction, mosquito monitoring, or surveillance. This study compared the performance of four aspiration traps in Germany (Biogents Sentinel trap (BG trap), Heavy Duty Encephalitis Vector Survey trap (EVS trap), Centres for Disease Control miniature light trap (CDC trap), and Mosquito Magnet Patriot Mosquito trap (MM trap)), which are commonly used in Central Europe. During the study period we found all mosquito species, which are known to be abundant in Germany. The four traps detected a 
Table 4 Statistical differences between the number of trapped individuals per species and the total number of individuals among the four trapping devices

\begin{tabular}{|c|c|c|c|c|c|c|}
\hline $\begin{array}{l}\text { Response } \\
\text { variable }\end{array}$ & Traps & Estimate & SE & DF & $t$ & $p$ \\
\hline \multirow{4}{*}{$\begin{array}{l}\text { Anopheles } \\
\text { plumbeus }\end{array}$} & BG vs. CDC & 0.641 & 0.299 & 301.2 & 2.14 & 0.033 \\
\hline & BG vs. EVS & 0.858 & 0.299 & 301.2 & 2.87 & 0.004 \\
\hline & CDC vs. MM & -1.032 & 0.307 & 302.1 & -3.36 & 0.001 \\
\hline & EVS vs. MM & -1.249 & 0.307 & 302.1 & -4.07 & $<0.001$ \\
\hline \multirow{3}{*}{$\begin{array}{l}\text { Aedes } \\
\text { cinereus/ } \\
\text { geminus }\end{array}$} & BG vs. $C D C$ & 9.304 & 2.354 & 301 & 3.95 & $<0.001$ \\
\hline & BG vs. EVS & 10.002 & 2.354 & 301 & 4.25 & $<0.001$ \\
\hline & BG vs. MM & 6.052 & 2.418 & 301.3 & 2.5 & 0.013 \\
\hline \multirow{3}{*}{$\begin{array}{l}\text { Aedes } \\
\text { vexans }\end{array}$} & BG vs. CDC & -32.42 & 7.296 & 301.1 & -4.44 & $<0.001$ \\
\hline & CDC vs. EVS & 20.566 & 7.293 & 301.1 & 2.82 & 0.005 \\
\hline & CDC vs. MM & 28.547 & 7.49 & 301.7 & 3.81 & $<0.001$ \\
\hline \multirow{5}{*}{$\begin{array}{l}\text { Ochlerotatus } \\
\text { cantans }\end{array}$} & BG vs. CDC & 7.732 & 2.456 & 301.1 & 3.15 & 0.002 \\
\hline & BG vs. EVS & 8.877 & 2.456 & 301.1 & 3.61 & $<0.001$ \\
\hline & BG vs. MM & 13.929 & 2.524 & 301.4 & 5.52 & $<0.001$ \\
\hline & CDC vs. MM & 6.197 & 2.523 & 301.4 & 2.46 & 0.015 \\
\hline & EVS vs. MM & 5.052 & 2.523 & 301.4 & 2 & 0.046 \\
\hline \multirow{3}{*}{$\begin{array}{l}\text { Ochlerotatus } \\
\text { communis }\end{array}$} & BG vs. $C D C$ & 1.11 & 0.427 & 301 & 2.6 & 0.01 \\
\hline & BG vs. EVS & 1.11 & 0.427 & 301 & 2.6 & 0.01 \\
\hline & BG vs. MM & 1.497 & 0.439 & 301.2 & 3.41 & 0.001 \\
\hline \multirow{2}{*}{$\begin{array}{l}\text { Ochlerotatus } \\
\text { excrucians/ } \\
\text { annulipes }\end{array}$} & BG vs. EVS & 0.299 & 0.138 & 301.3 & 2.17 & 0.031 \\
\hline & BG vs. MM & 0.418 & 0.142 & 302.6 & 2.95 & 0.003 \\
\hline \multirow{4}{*}{$\begin{array}{l}\text { Ochlerotatus } \\
\text { geniculatus }\end{array}$} & BG vs. EVS & 1.144 & 0.466 & 301.1 & 2.45 & 0.015 \\
\hline & BG vs. MM & -1.039 & 0.479 & 301.6 & -2.17 & 0.031 \\
\hline & CDC vs. MM & -1.845 & 0.479 & 301.6 & -3.85 & $<0.001$ \\
\hline & EVS vs. MM & -2.183 & 0.479 & 301.6 & -4.56 & $<0.001$ \\
\hline $\begin{array}{l}\text { Ochlerotatus } \\
\text { punctor }\end{array}$ & BG vs. MM & 0.976 & 0.334 & 301.2 & 2.92 & 0.004 \\
\hline \multirow{3}{*}{$\begin{array}{l}\text { Ochlerotatus } \\
\text { rusticus }\end{array}$} & BG vs. $C D C$ & 4.198 & 1.764 & 301 & 2.38 & 0.018 \\
\hline & BG vs. EVS & 7.246 & 1.764 & 301 & 4.11 & $<0.001$ \\
\hline & EVS vs. MM & -5.159 & 1.812 & 301.2 & -2.85 & 0.005 \\
\hline \multirow{5}{*}{$\begin{array}{l}\text { Ochlerotatus } \\
\text { sticticus/ } \\
\text { diantaeus }\end{array}$} & BG vs. EVS & 5.248 & 1.373 & 301 & 3.82 & $<0.001$ \\
\hline & BG vs. MM & 5.675 & 1.411 & 301.2 & 4.02 & $<0.001$ \\
\hline & CDC vs. EVS & 3.542 & 1.373 & 301 & 2.58 & 0.01 \\
\hline & CDC vs. MM & 3.969 & 1.411 & 301.2 & 2.81 & 0.005 \\
\hline & BG vs. CDC & 8.957 & 2.797 & 301.1 & 3.2 & 0.002 \\
\hline
\end{tabular}

Table 4 Statistical differences between the number of trapped individuals per species and the total number of individuals among the four trapping devices (Continued)

culex

pipiens/

torrentium

$\begin{array}{lllllll} & \text { BG vs. EVS } & 6.475 & 2.797 & 301.1 & 2.31 & 0.021 \\ & \text { BG vs. MM } & 17.026 & 2.873 & 302 & 5.93 & <0.001 \\ & \text { CDC vs. MM } & 8.069 & 2.872 & 301.9 & 2.81 & 0.005 \\ \text { Culiseta } & \text { EVS vs. MM } & 10.55 & 2.872 & 301.9 & 3.67 & <0.001 \\ \text { annulata } & \text { BG vs. EVS } & -0.975 & 0.347 & 300.8 & -2.81 & 0.005 \\ & & & & & & \\ \text { Total } & \text { EVS vs. MM } & 0.703 & 0.357 & 301.4 & 1.97 & 0.05 \\ & \text { BG vs. EVS } & 30.106 & 10.598 & 301 & 2.84 & 0.005 \\ \text { Species } & \text { BG vs. MM } & 41.781 & 10.889 & 301.3 & 3.84 & <0.001 \\ & \text { CDC vs. EVS } & 30.289 & 10.595 & 301 & 2.86 & 0.005 \\ & \text { CDC vs. MM } & 41.965 & 10.885 & 301.3 & 3.86 & <0.001 \\ & \text { BG vs. CDC } & 0.446 & 0.215 & 301 & 2.08 & 0.039 \\ & \text { BG vs. EVS } & 0.531 & 0.215 & 301 & 2.47 & 0.014 \\ & \text { BG vs. MM } & 0.619 & 0.221 & 301.1 & 2.8 & 0.005\end{array}$

Mean +/-SE differences in least squares means associated with the mixed linear models for the number of trapped individuals per trapping period for each species and the total number of individuals and the mean +/-SE number of species among the four trapping devices. Only mosquito species caught with more than 100 individuals are shown and trapping periods were only included if the species was detected with at least one individual in the corresponding trapping period at the sampling location (only significant differences shown). BG: Biogents Sentinel trap, EVS: Heavy Duty Encephalitis Vector Survey trap, CDC: Centres for Disease Control miniature light trap, MM: Mosquito Magnet Patriot Mosquito trap, Estimate: differences in least squares means, SE: standard error, DF: degrees of freedom, $t$ : $t$-value, $p: p$ value.

similar number of species. However, the BG trap was found to trap the largest diversity of mosquito species per trapping period, while there were no differences between the other three traps. Additionally, the BG and CDC traps caught more mosquito individuals per trapping period than the EVS and MM traps. This matches a trap comparison from the Netherlands, which found the CDC trap catching more individuals than the MM trap [20]. In the same study, the CDC trap was found to catch more species than the MM trap, a result that is not supported by our study. Our results are also in contrast to a trap comparison from Great Britain, which identified the MM trap to catch more species and individuals than the CDC trap [19].

Contrary to a Spanish study [22], which did not find differences between $\mathrm{CDC}$ and BG traps in collecting $C x$. pipiens, our study indicated that the BG trap caught significantly more $C x$. pipiens/torrentium per trapping period compared to the other three trapping devices. Our findings are in agreement with results of Reusken et al. [20], who showed a very low trapping efficacy of the MM trap for $C x$. pipiens/torrentium, while Drago et al. [10] did not find significant differences between 


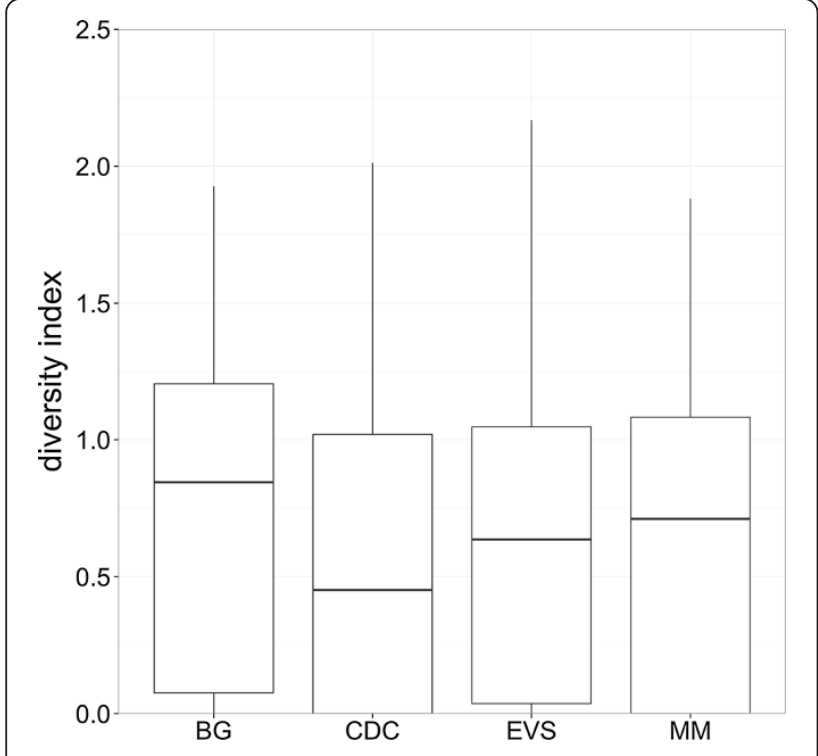

Figure 5 Simpson's diversity index among the four trapping devices. Boxplots of Simpson's diversity indices per trapping period among the four trapping devices.

BG and CDC traps for these species. Furthermore, the BG trap outperformed the other three traps for the three floodwater species Oc. cantans, Ae. cinereus/geminus and Oc. communis. A high trapping efficacy of the BG trap for members of the genera Aedes and Ochlerotatus was supported by several studies [reviewed by 10]. The MM trap also had the lowest performance for Oc. cantans.

The CDC and MM traps performed better than the other three traps for one particular species each. The
CDC trap caught the highest number of Ae. vexans per trapping period, which matches the results of a study from the U.S. [39], in which the CDC trap performed better than the BG trap. In contrast, another U.S. study did not find clear differences between the BG and CDC trap [14]. Our study showed that the MM trap caught the highest number of Oc. geniculatus, which is in agreement with a study from the U.K., in which the MM trap caught more individuals of this species compared to the CDC trap [19].

The four trapping devices used in this study differ in constructions and mechanisms to lure and trap mosquitoes. Except for the addition of a dry ice bucket to the CDC trap, we used the traps according to the manufacturers' instructions and did not interfere with recommended trap configurations (e.g. with lure vs. without lure or different heights). However, changes of configurations might result in a different performance of the various traps.

Although the $\mathrm{CO}_{2}$-effusion rate from dry ice (CDC and EVS traps) is probably more temperature-dependent than from gas cylinders (BG trap), this probably does not have a strong impact on the trapping efficacy. The same probably applies to the amount of $\mathrm{CO}_{2}$ and the type of $\mathrm{CO}_{2}$ dispersal from small holes on the EVS dry ice bucket (EVS and CDC traps) or tubes (BG and MM traps) [13], which should not cause profound differences between the traps. However, it is surprising that the CDC trap revealed significantly higher trapping efficacy for the species Ae. vexans and Oc. sticticus/diantaeus compared to the rather similar EVS trap. The trap cover of the CDC trap (33 $\mathrm{cm}$ in diameter) has a positive

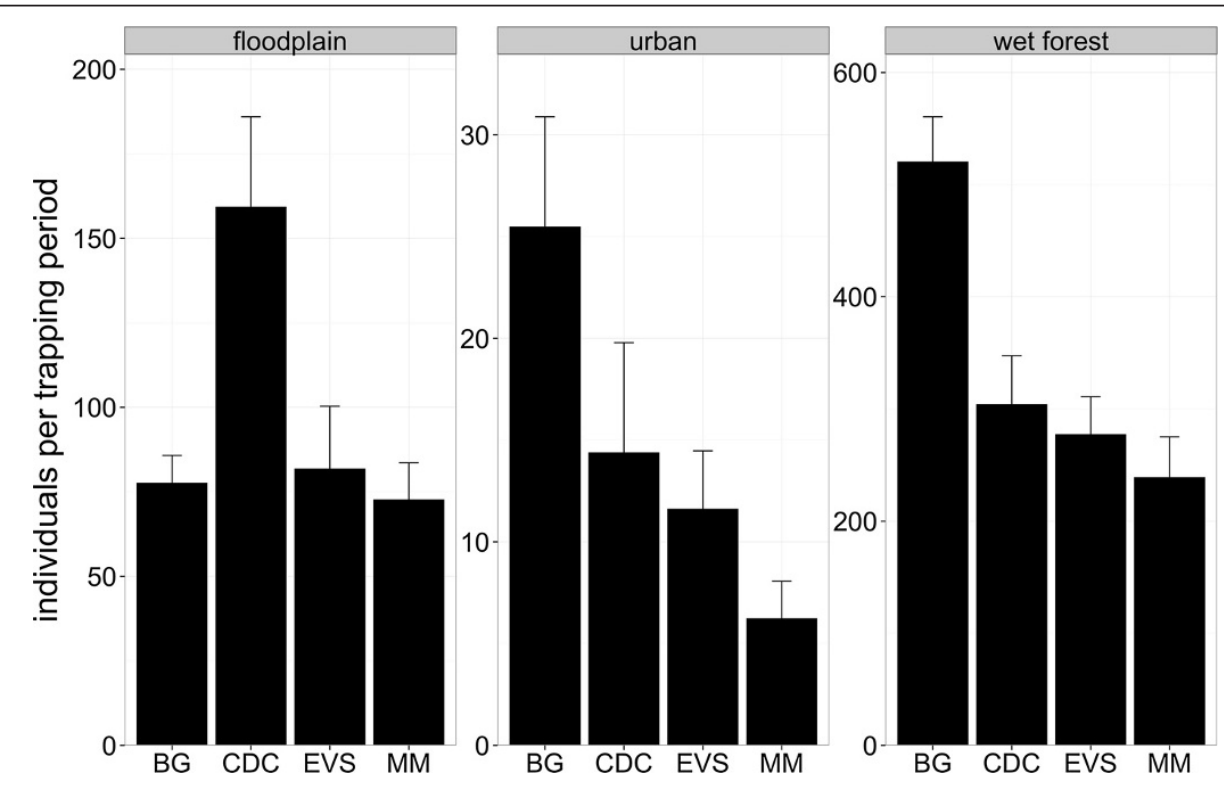

Figure 6 Number of individuals per aggregated biotope among the four trapping devices. Mean $+/-S E$ number of trapped individuals per trapping period among the four trapping devices and the three aggregated biotopes. 
Table 5 Statistical differences between the number of trapped individuals among the four trapping devices and aggregated biotopes

\begin{tabular}{llllllll}
\hline Response variable & Biotope & Traps & Estimate & SE & DF & $\mathbf{t}$ & $\mathbf{p}$ \\
\hline Total & Floodplain & BG vs. CDC & -81.304 & 22.617 & 98.2 & -3.59 & 0.001 \\
& Floodplain & CDC vs. EVS & 77.536 & 22.597 & 98.1 & 3.43 & 0.001 \\
& Floodplain & CDC vs. MM & 82.400 & 23.742 & 99.2 & 3.47 & 0.001 \\
& Urban & BG vs. CDC & 11.106 & 5.247 & 168.1 & 2.12 & 0.036 \\
& Urban & BG vs. EVS & 13.851 & 5.247 & 168.1 & 2.64 & 0.009 \\
& Urban & BG vs. MM & 20.203 & 5.430 & 169.1 & 3.72 & $<0.001$ \\
& Wet forest & BG vs. CDC & 216.625 & 38.277 & 27.0 & 5.66 & $<0.001$ \\
& Wet forest & BG vs. EVS & 243.375 & 38.277 & 27.0 & 6.36 & $<0.001$ \\
& Wet forest & BG vs. MM & 281.750 & 38.277 & 27.0 & 7.36 & $<0.001$ \\
\hline
\end{tabular}

Mean +/-SE differences in least squares means associated with the mixed linear models for the number of trapped individuals per trapping period among the four trapping devices and the three aggregated biotopes (only significant differences shown). BG: Biogents Sentinel trap, EVS: Heavy Duty Encephalitis Vector Survey trap, CDC: Centres for Disease Control miniature light trap, MM: Mosquito Magnet Patriot Mosquito trap, Estimate: differences in least squares means, SE: standard error, DF: degrees of freedom, t: $t$-value, $p: p$ value.

impact on the diffusion range of the $\mathrm{CO}_{2}$ [40], which may result in significant trapping differences for this very abundant species. Another explanation could be the secondary attractant of light, which is only used with the CDC trap. However, the study by Becker et al. [41] did not reveal a significant impact of light on the trapping efficacy of the CDC trap for Aedes.

The BG and MM traps use different chemical lures additional to carbon dioxide to increase their trapping efficacy by imitating the olfactory cues of potential hosts (e.g. octenol for ruminant breaths or lactic acid as component of sweat) [42]. Such lures can have significant influences on the trapping efficacy for particular mosquito species, but do not necessarily cause differences
$[21,22,42]$. Only for An. plumbeus there was a a significantly better performance for the two lure-containing traps (BG and MM traps) compared to those without lure (CDC and EVS traps). However, with the exception of Oc. geniculatus, the BG trap performed similar or even better compared to the MM trap. Although the BG Lure used for the BG traps might explain the better performance for some of the species, it probably does not explain the differences for all of them, as there were no significant differences for the trapping of $C x$. pipiens with and without BG Lure in a previous German study [21].

We conducted our trap comparison at ten sampling locations distributed in northern and southern Germany, which were analysed as aggregated biotopes for floodplain,

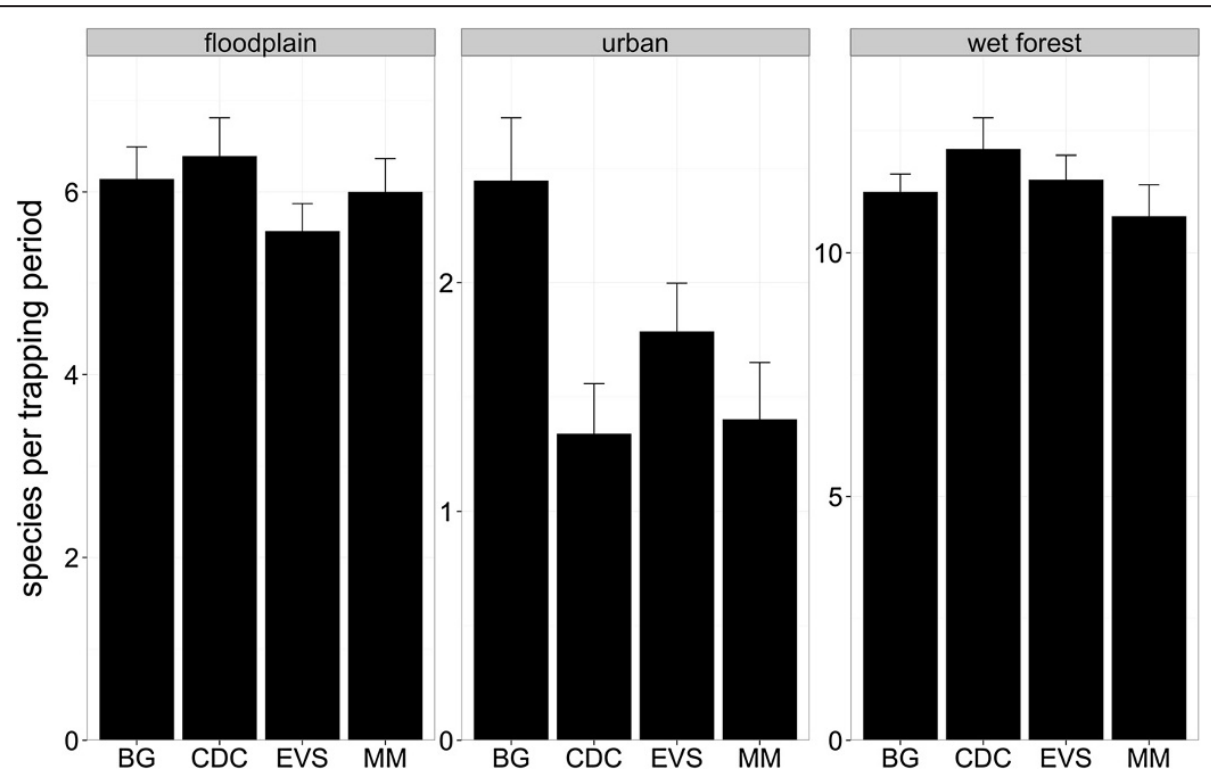

Figure 7 Number of species among the four trapping devices and aggregated biotopes. Mean $+/-S E$ number of trapped species per trapping period among the four trapping devices and the three aggregated biotopes. 
Table 6 Statistical differences between the number of trapped species among the four trapping devices and aggregated biotopes

\begin{tabular}{llllllll}
\hline Response variable & Biotope & Traps & Estimate & SE & DF & t & p \\
\hline Species & Urban & BG vs. CDC & 1.106 & 0.249 & 168.0 & 4.44 & $<0.001$ \\
& Urban & BG vs. EVS & 0.660 & 0.249 & 168.0 & 2.65 & 0.009 \\
& Urban & BG vs. MM & 0.981 & 0.258 & 168.5 & 3.80 & $<0.001$ \\
\hline
\end{tabular}

Mean +/-SE differences in least squares means associated with the mixed linear models for the number of trapped species per trapping period among the four trapping devices and the three aggregated biotopes (only significant differences shown). BG: Biogents Sentinel trap, EVS: Heavy Duty Encephalitis Vector Survey trap, CDC: Centres for Disease Control miniature light trap, MM: Mosquito Magnet Patriot Mosquito trap, Estimate: differences in least squares means, SE: standard error, DF: degrees of freedom, t: t-value, $p$ : $p$ value.

urban and wet forest, respectively. According to its trapping performance for Culex species, we found the BG trap to be superior in an urban environment. The CDC trap was the most efficient trapping device for Aedes vexans and therefore should be the first choice for the floodplain environment and the BG trap showed an outstanding performance for some of the snow-melt mosquito species and therefore trapped most mosquito individuals in the wet forest.

\section{Conclusion}

This study compared four adult mosquito traps (BG trap, EVS trap, CDC trap, and MM trap) under different environmental conditions in Germany with a total of 323 24-hour sampling periods $(83 \times$ BG trap, $83 \times \mathrm{CDC}$ trap, $83 \times$ EVS trap, $74 \times$ MM trap) and the analysis of more than 24,000 mosquitoes from 21 species most common in Central Europe. The BG trap showed the best performance regarding the number of mosquitoes and the number of mosquito species per trapping period and outperformed the other three traps for the genus Culex and for four species (Oc. cantans, Ae. cinereus/ geminus, Oc. communis and Cx. pipiens/torrentium). The CDC trap was the most efficient trap for Ae. vexans and the MM trap for the genus Anopheles and the species Oc. geniculatus. The EVS trap did not show advantages for any species or genus compared to the other three traps. Additionally, the MM trap had a very low efficacy for Cx. pipiens/torrentium and Oc. cantans. According to its efficacy for the number of mosquitoes and the range of species at various environments, the BG trap is recommended as the general monitoring trapping device for common mosquito species in Central Europe, while the CDC trap is the best choice to trap large numbers of mosquitoes particularly in floodplain biotopes.

\section{Additional file}

Additional file 1: Mosquito species not caught with the four different trapping devices. Description of data: Mosquito species not caught with the four different trapping devices. Occurrence in Germany classified after Becker et al. [38] (occurrence: ++ = frequent; += regularly; $(+)=$ rare; $-=$ not classified; * species is not established; $\square=$ not counted in the species lists).

\section{Competing interests}

Over the last three years, the company Biogents, which is the producer of the $B G$ mosquito traps included in this study, was a research partner of the authors NB, KH, EK, AK, RL, WPP and ET in a surveillance study for invasive mosquitoes in Germany. Biogents had no role in study design, data collection and analysis, preparation of the manuscript or decision on publication.

\section{Authors' contributions}

Designed the study: AK, RL, WPP, EK. Performed the data collection: JB, RG, $\mathrm{KH}, \mathrm{AK}, \mathrm{RL}, \mathrm{NS}, \mathrm{SS}, \mathrm{NB}, \mathrm{ET}, \mathrm{WPP}$. Analysed the data: RL. Wrote the paper: RL. Contributed to the manuscript drafting: AK, ET, WPP, RG, EK, NS, SS. All authors read and approved the final version of the manuscript.

\section{Acknowledgements}

This work was financially supported by the German Federal Ministry for the Environment, Nature Conservation, Building and Nuclear Safety (BMUB) through the Federal Environment Agency (UBA), grant number FKZ371148404 and by the Leibniz Association, grant number SAW-2011-BNI-3.

\section{Author details}

${ }^{1}$ Department of Molecular Parasitology, Bernhard Nocht Institute for Tropical Medicine, Hamburg, Germany. ${ }^{2}$ Research Group Aquatic Ecology and Nature Conservation, Carl von Ossietzky University, Oldenburg, Germany. ${ }^{3}$ German Mosquito Control Association (KABS e.V.), Institute for Dipterology, Waldsee, Germany. ${ }^{4}$ Department of Virology, Bernhard Nocht Institute for Tropical Medicine, Hamburg, Germany. 5 University of Heidelberg, Heidelberg, Germany. ${ }^{6}$ German Centre for Infection Research, partner site Hamburg-Luebeck-Borstel, Hamburg, Germany. ${ }^{7}$ Department of Tropical Medicine, Bundeswehr Hospital Hamburg, Hamburg, Germany.

Received: 11 April 2014 Accepted: 4 June 2014

Published: 12 June 2014

\section{References}

1. Versteirt V, Boyer S, Damiens D, De Clercq EM, Dekoninck W, Ducheyne E, Grootaert P, Garros C, Hance T, Hendrickx G, Coosemans M, Van Bortel W: Nationwide inventory of mosquito biodiversity (Diptera: Culicidae) in Belgium, Europe. Bull Entomol Res 2012, 103:193-203.

2. Becker N, Geier M, Balczun C, Bradersen U, Huber K, Kiel E, Krüger A, Lühken R, Orendt C, Plenge-Bönig A, Rose A, Schaub GA, Tannich E: Repeated introduction of Aedes albopictus into Germany, July to October 2012. Parasitol Res 2013, 112:1787-1790.

3. Jöst H, Bialonski A, Maus D, Sambri V, Eiden M, Groschup MH, Gunther S, Becker N, Schmidt-Chanasit J: Isolation of Usutu virus in Germany. Am J Trop Med Hyg 2011, 85:551-553.

4. Jackson MJ, Gow JL, Evelyn MJ, McMahon TJS, Howay TJ, Campbell H, Blancard J, Thielman A: An evaluation of the effectiveness of a commercial mechanical trap to reduce abundance of adult nuisance mosquito populations. J Am Mosq Control Assoc 2012, 28:292-300.

5. Kaufman MG, Fonseca DM: Invasion biology of Aedes japonicus japonicus (Diptera: Culicidae). Annu Rev Entomol 2014, 59:31-49.

6. Kampen H, Werner D: Out of the bush: the Asian bush mosquito Aedes japonicus japonicus (Theobald, 1901) (Diptera, Culicidae) becomes invasive. Parasit Vectors 2014, 7:59. 
7. Bonizzoni M, Gasperi G, Chen X, James AA: The invasive mosquito species Aedes albopictus: current knowledge and future perspectives. Trends Parasitol 2013, 29:460-468.

8. Gubler DJ: The continuing spread of West Nile virus in the western hemisphere. Clin Infect Dis 2007, 45:1039-1046.

9. Kröckel U, Rose A, Eiras ÀE, Geier M: New tools for surveillance of adult yellow fewer mosquitoes: comparison of trap catches with human landing rates in an urban environment. J Am Mosa Control Assoc 2006, 22:229-238

10. Drago A, Marini F, Caputo B, Coluzzi M, Torre A d, Pombi M: Looking for the gold standard: assessment of the effectiveness of four traps for monitoring mosquitoes in Italy. J Vector Ecol 2012, 37:117-123.

11. Silver JB: Mosquito Ecology Field Sampling Methods. Dordrecht, the Netherlands: Springer; 2008:1477.

12. Dennett JA, Vessey NY, Parsons RE: A comparison of seven traps used for collection of Aedes albopictus and Aedes aegypti originating from a large tire repository in Harris county (Houston), Texas. J Am Mosa Control Assoc 2004, 20:342-349.

13. Irish SR, Chandre F, N'Guessan R: Comparison of octenol- and BG Lure ${ }^{\circledR}$ baited Biogents Sentinel traps and an encephalitis virus surveillance trap in Portland, OR. J Am Mosa Control Assoc 2008, 24:393-397.

14. Farajollahi A, Kesavaraju B, Price DC, Williams GM, Healy SP, Gaugler R, Nelder MP: Field efficacy of BG-Sentinel and industry-standard traps for Aedes albopictus (Diptera: Culicidae) and West Nile virus surveillance. J Med Entomol 2009, 46:919-925.

15. Hoel DF, Kline DL, Allan SA: Evaluation of six mosquito traps for collection of Aedes albopictus and associated mosquito species in a suburban setting in north central Florida. J Am Mosq Control Assoc 2009, 25:47-57.

16. Medlock JM, Hansford KM, Schaffner F, Versteirt V, Hendrickx G, Zeller H, Bortel W: A review of the invasive mosquitoes in Europe: ecology, public health risks, and control options. Vector-Borne Zoonotic Dis 2012, 12:435-447

17. Sambri V, Capobianchi M, Charrel R, Fyodorova M, Gaibani P, Gould E, Niedrig M, Papa A, Pierro A, Rossini G, Varani S, Vocale C, Landini MP: West Nile virus in Europe: emergence, epidemiology, diagnosis, treatment, and prevention. Clin Microbiol Infect 2013, 19:699-704.

18. Engler O, Savini G, Papa A, Figuerola J, Groschup M, Kampen H, Medlock J, Vaux A, Wilson A, Werner D, Jöst H, Goffredo M, Capelli G, Federici V, Tonolla M, Patocchi N, Flacio E, Portmann J, Rossi-Pedruzzi A, Mourelatos S, Ruiz S, Vázquez A, Calzolari M, Bonilauri P, Dottori M, Schaffner F, Mathis A, Johnson N: European surveillance for West Nile virus in mosquito populations. Int J Environ Res Public Health 2013, 10:4869-4895.

19. Hutchinson RA, West PA, Lindsay SW: Suitability of two carbon dioxidebaited traps for mosquito surveillance in the United Kingdom. Bull Entomol Res 2007, 97:591-597.

20. Reusken C, De Vries A, Ceelen E, Beeuwkes J, Scholte E-J: A study of the circulation of West Nile virus, Sindbis virus, Batai virus and Usutu virus in mosquitoes in a potential high-risk area for arbovirus circulation in the Netherlands, "De Oostvaardersplassen.". Eur Mosq Bull 2011, 29:66-81.

21. Rose A, Kröckel U, Bergbauer R, Geier M, Eiras ÁE: Der BG-Sentinel, eine neuartige Stechmückenfalle für Forschung und Überwachung. (The BG-Sentinel, a novel mosquito trap for research and surveillance.). Mitteilungen Dtsch Ges Für Allg Angew Entomol 2006, 15:345-348.

22. Roiz D, Roussel M, Munoz J, Ruiz S, Soriguer R, Figuerola J: Efficacy of mosquito traps for collecting potential West Nile mosquito vectors in a natural Mediterranean wetland. Am J Trop Med Hyg 2012, 86:642-648.

23. Lundström JO, Schäfer ML, Hesson JC, Blomgren E, Lindström A, Wahlqvist P, Halling A, Hagelin A, Ahlm C, Evander M, Broman T, Forsman M, Persson Vinnersten TZ: The geographic distribution of mosquito species in Sweden. J Eur Mosa Control Assoc 2013, 31:21-35.

24. Versteirt V, De Clercq E, Dekoninck W, Damiens D, Ayrinhac A, Jacobs F, Van Bortel W: Mosquito Vectors of Disease: Spatial Biodiversity, Drivers of Change, and Risk. Final Report. Belgian Science Policy: Brussels; 2009.

25. Rudolf M, Czajka C, Börstler J, Melaun C, Jöst H, von Thien H, Badusche M, Becker N, Schmidt-Chanasit J, Krüger A, Tannich E, Becker S: First nationwide surveillance of Culex pipiens complex and Culex torrentium mosquitoes demonstrated the presence of Culex pipiens biotype pipiens/ molestus hybrids in Germany. PLoS One 2013, 8:e71832.

26. DWD: DWD. http://www.dwd.de/bvbw/appmanager/bvbw/dwdwwwDesktop?_ nfpb=true\&_pageLabel=_dwdwww_klima_umwelt_klimadaten_deutschland \&T82002gsbDocumentPath=Navigation\%2FOeffentlichkeit\%2FKlima_Umwelt\%
2FKlimadaten\%2Fkldaten_kostenfrei\%2Fausgabe_tageswerte_node.htm|\% 3F_nnn\%3Dtrue.

27. Mohrig W: Die Culiciden Deutschlands. Jena: Gustav Fischer; 1969:260 [Parasitologische Schriftenreihe, vol. 18].

28. Becker N, Petric D, Zgomba M, Boase C, Madon M, Dahl C, Kaiser A: Mosquitoes and Their Control. 2nd edition. Heidelberg: Springer; 2010:577.

29. Reinert JF, Harbach RE, Kitching IJ: Phylogeny and classification of tribe Aedini (Diptera: Culicidae). Zool J Linn Soc 2009, 157:700-794.

30. R Development Core Team: R: A Language and Environment for Statistical Computing. 212th edition. Vienna, Austria: R Foundation for Statistical Computing; 2010.

31. Wickham H: ggplot2: Elegant Graphics for Data Analysis. New York: Springer; 2009:213.

32. Bates D, Maechler M, Bolker B, Walker S: Ime4: Linear Mixed-Effects Models Using Eigen and S4. 2014

33. Kuznetsova A, Brockhoff PB, Christensen RHB: ImerTest: Tests for Random and Fixed Effects for Linear Mixed Effect Models (Imer Objects of Ime4 Package). 2013.

34. Wickham H: The split-apply-combine strategy for data analysis. J Stat Softw 2011, 40:1-29.

35. Pebesma EJ, Bivand RS: Classes and methods for spatial data in R. R News 2005, 5:9-13.

36. Roger S, Bivand RS, Pebesma EJ: Applied Spatial Data Analysis with R. New York: Springer; 2013:390

37. Oksanen J, Blanchet FG, Kindt R, Legendre P, Minchin PR, O'Hara RB, Simpson GL, Solymos P, Stevens MHH, Wagner H: Vegan: Community Ecology Package. 2013.

38. Becker N, Hoffmann D: First record of Culiseta longiareolata (Macquart) for Germany. Eur Mosq Bull 2011, 29:143-150.

39. Bhalala $H$, Arias JR: The Zumba ${ }^{T M}$ mosquito trap and BG-Sentinel ${ }^{T M}$ trap: novel surveillance tools for host-seeking mosquitoes. J Am Mosq Control Assoc 2009, 25:134-139.

40. Ritchie SA, Kline DL: Comparison of CDC and EVS light traps baited with carbon dioxide and octenol for trapping mosquitoes in Brisbane, Queensland (Diptera: Culicidae). Aust J Entomol 1995, 34:215-218.

41. Becker N, Zgomba M, Petric D, Ludwig M: Comparison of carbon dioxide octenol and a host-odour as mosquito attractants in the Upper Rhine Valley, Germany. Med Vet Entomol 1995, 9:377-380.

42. Hoel DF, Kline DL, Allan SA, Grant A: Evaluation of carbon dioxide, 1-octen-3-ol, and lactic acid as baits in mosquito magnet Pro traps for Aedes albopictus in north central Florida. J Am Mosq Control Assoc 2007, 23:11-17.

doi:10.1186/1756-3305-7-268

Cite this article as: Lühken et al:: Field evaluation of four widely used mosquito traps in Central Europe. Parasites \& Vectors 2014 7:268.

\section{Submit your next manuscript to BioMed Central and take full advantage of:}

- Convenient online submission

- Thorough peer review

- No space constraints or color figure charges

- Immediate publication on acceptance

- Inclusion in PubMed, CAS, Scopus and Google Scholar

- Research which is freely available for redistribution 